Научная статья

УДК 338.2

DOI 10.18101/2304-4446-2021-3-40-45

\title{
ОСОБЕННОСТИ РАЗВИТИЯ СФЕРЫ ОБРАЗОВАНИЯ В РАМКАХ ЦИФРОВОЙ ЭКОНОМИКИ
}

\section{(C) Булгатова Юлия Сергеевна}

кандидат философских наук, доцент feu2001@mail.ru

(C) Раднаева Дашима Булатовна

обучающийся

radnaeva.1999@mail.ru

\section{(C) Дашеев Амгалан Андреевич}

обучающийся

a-dasheev@mail.ru

Бурятский государственный университет имени Доржи Банзарова Россия, 670000, г. Улан-Удэ, ул. Смолина, 24a

Аннотация. В рамках статьи раскрываются актуальные тенденции развития образовательной сферы под влиянием современной цифровой экономики. Приводится ряд толкований термина «цифровая экономика», а также воздействие этого явления на образовательный процесс в нашей стране. Определены базовые пути развития цифровизации в области образования, в частности, на уровне высшего образования. Отмечается, что сбалансированное и гармоничное развитие личности современного типа подразумевает интенсивное использование достижений цифровой экономики в рамках обучающего процесса. Цифровая экономика рассматривается как новый тип экономической реальности, который проявляется появлением больших потоков огромных баз данных и распределением сетей. На ее базе формируется будущий формат жизнедеятельности всего общества. Высокий уровень цифровизации поспособствует прогрессивному развитию общества практически в каждом аспекте.

Ключевые слова: цифровая экономика, информационные решения, сетевая работа, сфера образования, система образования

\section{Для цитирования}

Булгатова Ю. С., Раднаева Д. Б., Дашеев А. А. Особенности развития сферы образования в рамках цифровой экономики // Вестник Бурятского государственного университета. Экономика и менеджмент. 2021. № 3. С. 40-45.

Технологии XXI в. имеют общую направленность к глобальной цифровизации практически всех аспектов деятельности. Мы можем наблюдать революционные изменения информационной сферы и рост динамики глобализационных процессов. Совершенствование структуры социума и межсоциальных взаимодействий, в составе которых особенно значимая роль отводится цифровому развитию, обусловливает появление нового типа экономической реальности, так называемой цифровой экономики [1]. Этот тип экономического пространства характеризует- 
Ю. С. Булгатова, Д. Б. Раднаева, А. А. Дашеев. Особенности развития сферы образования в рамках цифровой экономики

ся наличием множественных потоков больших данных, сетевым взаимодействием и цифровой реальностью. В настоящее время цифровая экономика становится базисом всех представлений о будущем формате реальности в рамках всего общества [2].

В данный момент среди научного сообщества нет общепринятого понятия цифровой экономики ввиду множественных точек зрения. В соответствии с результатами российских исследований можно обозначить следующие термины, имеющие отношение к цифровой экономике: «электронная экономика», «новый технологический уклад мира», «API экономика», «экономика приложений» и «креативная экономика». В таблице 1 отражены высказывания и толкования касательно определения «цифровая экономика», которые даны различными деятелями [3].

Таблица 1

Основные определения термина «цифровая экономика»

\begin{tabular}{|c|c|}
\hline Автор/источник & Определение \\
\hline $\begin{array}{l}\text { Иванов В. В., д-р экон. наук, член- } \\
\text { корреспондент РАН }\end{array}$ & $\begin{array}{l}\text { «Цифровая экономика есть виртуальная ре- } \\
\text { альность, служащая дополнением к челове- } \\
\text { ческой среде» }\end{array}$ \\
\hline $\begin{array}{l}\text { Указ Президента РФ от } 9 \text { мая } 2017 \text { г. } \\
\text { № } 203 \text { «О Стратегии развития инфор- } \\
\text { мационного общества в Российской } \\
\text { Федерации на 2017-2030 годы» }\end{array}$ & $\begin{array}{l}\text { «Цифровая экономика - хозяйственная ра- } \\
\text { бота, в которой главным аспектом производ- } \\
\text { ства считаются данные в цифровой форме, } \\
\text { анализ больших массивов и применение ито- } \\
\text { гов анализа, которые в сравнении с базовы- } \\
\text { ми формами хозяйствования дают возмож- } \\
\text { ность значительно увеличить эффективность } \\
\text { разнообразных видов производства, техно- } \\
\text { логий, оборудования, хранения, продажи, } \\
\text { доставки товаров и услуг» }\end{array}$ \\
\hline $\begin{array}{l}\text { Путин В. В., президент Российской } \\
\text { Федерации }\end{array}$ & $\begin{array}{l}\text { «цфровая экономика - это способ дея- } \\
\text { тельности, гарантирующий быстроту и каче- } \\
\text { ство экономических процессов, но при этом } \\
\text { не подменяющий экономические порядки и } \\
\text { законы, профессиональные компетенции } \\
\text { инженерии и наработанный опыт в промыш- } \\
\text { ленности» }\end{array}$ \\
\hline
\end{tabular}

В приведенной таблице анализируется лишь небольшая часть всех возможных определений и форм данного понятия. В целом на базе ключевых положений мы можем дать комплексное определение. Цифровая экономика есть не что иное, как работа определенных субъектов, направленная на производство и продажу продукции или работ с помощью отправки, анализа и хранения массивных объемов данных и сведений с использованием достижений информационного развития.

\footnotetext{
${ }^{1}$ О Стратегии развития информационного общества в Российской Федерации на 20172030 гг.: указ Президента РФ от 09.05.2017. № 203. URL: www.consultant.ru (дата обращения: 08.07.2021). Текст: электронный.
} 
Такие достижения в условиях нынешнего социума применяются почти в каждой области социального развития, особенное внимание необходимо уделить образованию по той причине, что именно образование представляется фундаментом развития профессиональных компетенций каждого направления деятельности. Информационные технологии прочно входят в образовательный процесс на протяжении последних десятилетий в рамках всех ступеней и уровней обучения. Государство делает упор на развитие цифровизации образования в стремлении создать прочную кадровую базу развития государства в цифровом будущем [2].

Нынешний подход к направлению цифровизации образования включает в себя постоянный поток обмена знаниями и опытом [5]. В данный момент прослеживается рост применения таких базовых цифровых инструментов, как онлайнкурсы и дистанционное обучение, активно работают электронные библиотеки и цифровые кампусы многих вузов. Образование приобретает оттенок глобальности, все желающие могут получить к нему доступ, который ранее был ограничен. Ключевые цифровые инновации сегодня отражены на рисунке 1.

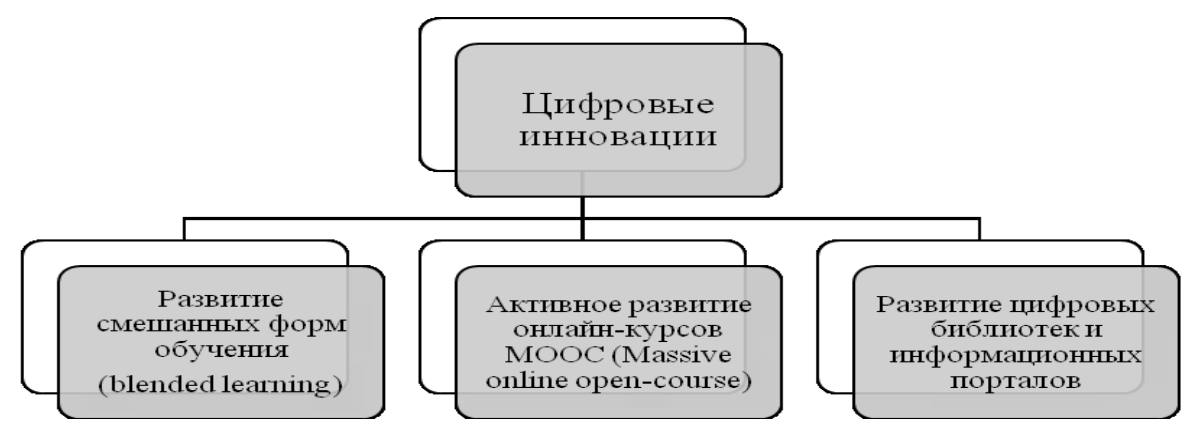

Рис. 1. Виды цифровых инноваций

Ведущие университеты мира всецело поддерживают тенденции цифровизации образования. Многие стремятся расширять международные кампусы, привлекать зарубежных специалистов, педагогов, учащихся, проводят мероприятия практического и образовательного характера. Безусловно, все крупные университеты так или иначе будут подвержены влиянию цифровизации в большей или меньшей степени. В процессе цифровизации будут вводиться новые технологические решения, инновации и изменения корпоративной культуры.

Подобные сдвиги являются жизненно необходимыми для вузов, так как нынешние студенты причисляются к поколению «digitalnatives», имеющие склонность к обучению новым технологиям и их имплементации в процессы общества. Чтобы качественно и полноценно выполнить цифровизацию образования, необходимо интенсивно вводить разнообразные информационные сервисы и порталы, электронные хранилища данных, развивать научные исследования в области инноваций [3].

Ключевые инструменты цифровизации университетов и их краткое описание даны в таблице 2. Университетам необходимо разрабатывать собственную стратегию инновационной работы на основе актуальных запросов современного общества и цифровой экономики в частности. Все эти аспекты формируют позитивный образ вуза. 
Ю. С. Булгатова, Д. Б. Раднаева, А. А. Дашеев. Особенности развития сферы образования в рамках цифровой экономики

Таблица 2

Основные методы цифровизации вузов

\begin{tabular}{|l|l|}
\hline \multicolumn{1}{|c|}{ Методы } & \multicolumn{1}{|c|}{ Характеристика } \\
\hline $\begin{array}{l}\text { Применение базовых } \\
\text { информационных серви- } \\
\text { сов }\end{array}$ & $\begin{array}{l}\text { Использование таких решений даст возможность выработать } \\
\text { объединённое цифровое пространство внутренней среды } \\
\text { учебного заведения. Для этого нужно задействовать ряд тех- } \\
\text { нологий, к примеру, экраны видеопрезентаций в кабинетах и } \\
\text { лекционных помещениях, облачные базы данных и т. д. }\end{array}$ \\
\hline $\begin{array}{l}\text { Создание цифровых } \\
\text { библиотек и электрон- } \\
\text { ных каталогов }\end{array}$ & $\begin{array}{l}\text { Появляется возможность получения доступа к научным пуб- } \\
\text { ликациям и трудам с разнообразных устройств, вне зависи- } \\
\text { мости от времени и места запроса }\end{array}$ \\
\hline $\begin{array}{l}\text { Цифровизация науко- } \\
\text { метрии }\end{array}$ & $\begin{array}{l}\text { Наблюдение, расширение и обработка данных наукометрии с } \\
\text { применением последних достижений накопления информа- } \\
\text { ции и анализа данных }\end{array}$ \\
\hline Цифровой маркетинг & $\begin{array}{l}\text { Проведение мероприятий для формирования положительного } \\
\text { имиджа вуза, узнаваемости бренда }\end{array}$ \\
\hline $\begin{array}{l}\text { Взаимодействие с аби- } \\
\text { туриентами и студента- } \\
\text { ми с помощью цифро- } \\
\text { вых технологий }\end{array}$ & $\begin{array}{l}\text { Скооперированная работа студентов, преподавателей, абиту- } \\
\text { риентов и выпускников на базе последних достижений циф- } \\
\text { ровых технологий и способов коммуникации, автоматизация } \\
\text { работы внутренних процессов в вузе }\end{array}$ \\
\hline
\end{tabular}

Трансформация учебного заведения в полноценный цифровой университет сопряжена с созданием соответственных обучающих программ современного типа, нацеленных на рост уровня цифрового образования, также нужно разрабатывать специальные методы преподавания и повышения квалификации педагогов [4].

Как итог введения программ по цифровизации обучения, учебное заведение создает множество конкурентных преимуществ. Внутриорганизационные механизмы будут в той же степени усовершенствованы благодаря цифровым технологиям.

Нужно подчеркнуть, что актуальные исследовательские данные о динамике роста цифровизации отражают нехватку возможностей реализации программ внедрения информационных технологий. В рейтинге из 50 мировых лидеров по внедрению цифровой экономики РФ в 2019 г. занимала 25-е место [3].

Целевыми направлениями в сфере развития цифровизации образования можно назвать следующие:

1) непрерывный мониторинг инновационных исследований и технологических новинок для их последующего применения;

2) стабильное совершенствование деятельности вуза с помощью введения в работу цифровых решений;

3) открытие доступа к хранилищам данных, к примеру, электронные библиотеки или интернет-порталы;

4) модернизация облачных механизмов для стимуляции инновационных процессов.

В настоящее время ведущие вузы России должны уделять внимание внедрению смарт-образования для дальнейшего выпуска высококвалифицированных специалистов, имеющих потенциал для ориентирования в крупных информаци- 
онных системах и современных цифровых технологиях. Потребность в подобных профессионалах год от года будет лишь возрастать в стремительных темпах с ростом мировой прослойки подобных кадров. При этом государству необходимо направить усилия на удержание ценных и талантливых сотрудников, предоставление всех необходимых условий работы и достойного финансового поощрения, большего, чем в странах-конкурентах. Эта проблема до сих пор окончательно не решена и в сегодняшней ситуации налицо значительный отток ценных кадров за рубеж.

Таким образом, в нынешней ситуации специалисты должны обладать соответствующей подготовкой с учетом требований новой цифровой реальности. Вузы все активнее внедряют информационные технологии самого разного свойства. При этом особое значение имеет трансформация образовательных услуг в цифровой вид и рост финансовой эффективности информационных решений.

На данном этапе развития социума быстро развиваются технологии цифровой экономики, влияя практически на все сферы деятельности, в том числе и образование. Качественная цифровизация образования в университете базируется на полноценном превращении вуза в цифровой университет. Интенсивное введение цифровых технологий способствует повышению комфорта студентов и преподавателей, обеспечивает прогрессивный образ и имидж университета.

Литература

1. Булгатова Ю. С., Сандаков Б. В. Блокчейн-технология как новый путь развития экономики России // Вестник Бурятского государственного университета. Экономика и менеджмент. 2018. № 1. С. 16-22. Текст: непосредственный.

2. Герасимов Г. А. Цифровые технологии для совершенствования образовательного процесса и воспитательной работы в дополнительном образовании. URL: https://moluch.ru/conf/ped/archive/150/7755/ (дата обращения: 08.07.2021). Текст: электронный.

3. Деткина Д. А. Объекты инновационной экосистемы университета и проблемы их развития // Экономика знаний: инновационная экосистема и новая индустриализация региона: материалы первого молодежного форума, Краснодар, 18-19 ноября 2016 г. Краснодар: Изд-во Кубанского гос. ун-та, 2019. С. 79-82. Текст: непосредственный.

4. Цыренов Д. Д. Оценка когнитивного потенциала студентов университета в условиях становления и развития экономики знаний // Вестник Бурятского государственного университета. Экономика и менеджмент. 2015. № 1. С. 52-58. Текст: непосредственный.

5. Прикладная бизнес-информатика: теория, методология, практика / Д. Д. Цыренов, А. Ю. Лосева, Я. С. Ясечко, Д. Ш. Цыренова. Улан-Удэ, 2016. 148 с. Текст: непосредственный.

Статья поступила в редакиию 13.07.2021; одобрена после рецензирования 30.07.2021; принята к публикации 18.08.2021. 


\section{FEATURES OF THE DEVELOPMENT OF EDUCATION SECTOR IN THE CONTEXT OF DIGITAL ECONOMY}

Yulia S. Bulgatova

Cand. Sci. (Philos.), A/Prof.

feu2001@mail.ru

Dashima B. Radnaeva

Student

radnaeva.1999@mail.ru

Amgalan A. Dasheev

Student

a-dasheev@mail.ru

Dorzhi Banzarov Buryat State University

24a Smolina St., Ulan-Ude 670000, Russia

Abstract. The article reveals the current trends in the development of education sector on the back of modern digital economy. We have given some interpretations of the term "digital economy", analyzed the impact of this phenomenon on the educational process in our country, and identified the ways of developing digitalization in the field of education, in particular, at the level of higher education. It is emphasized that the balanced and harmonious development of a modern type of personality implies the intensive use of the achievements of digital economy as part of the learning process. Digital economy is considered as a new type of economic reality, which is manifested by the large flows of huge databases and the distribution of networks. Digital economy determines the future life of the whole society. The high level of digitalization will contribute to the progressive development of society in almost every aspect.

Keywords: digital economy, software solutions, networking, education, education system

\section{For citation}

Bulgatova Yu. S., Radnaeva D. B., Dasheev A. A. Features of the Development of Education Sector in the Context of Digital Economy. Bulletin of Buryat State University. Economy and Management. 2021; 3: 40-45 (In Russ.).

The article was submitted 13.07.2021; approved after reviewing 30.07.2021; accepted for publication 18.08.2021. 